\title{
The value of plantation forests for plant, invertebrate and bird diversity and the potential for cross-taxon surrogacy
}

\author{
Sandra Irwin ${ }^{1}$, Linda Coote ${ }^{2}$, Scott M. Pedley ${ }^{1}$, Anke C. Dietzsch², Mark W. Wilson ${ }^{1}$, Anne \\ Oxbrough $^{3}$, Oisín Sweeney ${ }^{1}$, Karen M. Moore ${ }^{2}$, Rebecca Martin ${ }^{1}$, Daniel L. Kelly², Fraser J. G., \\ Mitchell ${ }^{2}$, Thomas C. Kelly ${ }^{1}$ \& John O'Halloran ${ }^{1}$
}

${ }^{1}$ School of Biological, Earth \& Environmental Sciences, University College Cork, Ireland
${ }^{2}$ Department of Botany, School of Natural Sciences, Trinity College Dublin, Ireland
${ }^{3}$ Department of Biology, Edge Hill University, St Helens Road, Ormskirk, Lancashire L39 4QP, UK

Corresponding author: Email: s.irwin@ucc.ie, TEL: +353 21 4904595, FAX: +353 214904664

\begin{abstract}
As the area of plantation forest expands worldwide and natural, unmanaged forests decline there is much interest in the potential for planted forests to provide habitat for biodiversity. In regions where little semi-natural woodland remains, the biodiversity supported by forest plantations may be particularly important. Few biodiversity studies provide detailed comparisons between native woodlands and plantations, based on data collected from multiple taxa in the same study sites. Here we compare the diversity and community composition of plants, invertebrates and birds in Sitka spruce- and Norway spruce-dominated plantations, which have expanded significantly in recent decades in the study area in Ireland, with that of oak- and ash-dominated semi-natural woodlands in the same area. The results show that species richness in spruce plantations can be as high as semi-natural woodlands, but that the two forest types support different assemblages of species. In areas where plantations are the principle forest type, forest biodiversity can be enhanced through appropriate management of plantations, as well as by protecting and extending native woodlands. Our data show that although some relatively easily surveyed groups, such as vascular plants and birds, were congruent with many of the other taxa when looking across all study sites, the similarities in response were not strong enough to warrant use of these taxa as surrogates of the others. In order to capture a wide range of biotic variation, assessments of forest
\end{abstract}


biodiversity should either encompass several taxonomic groups, or rely on the use of indicators of diversity that are not species based.

Keywords: Beetles, Birds, Biodiversity, Forest, Management, Spiders, Vegetation

\section{Introduction}

Despite extensive deforestation in many countries across the world the area of commercial plantation forest is increasing (FAO 2012) and these forests are now the dominant forest type in many countries (European Commission 2011). Many plantation forests use exotic tree species, particularly conifer species (FAO 2012). The biodiversity of plantation forests can be influenced by management practices at both landscape and local scales (Kuuluvainen 2009; Klenner et al. 2009; Fabbio et al. 2003; Brukas et al. 2013). The prevalent model of forest management in the twentieth century focused almost entirely on wood production, but pressures from international agreements and societal demands are acting to make modern forest management more multifunctional. The implications of commercial plantation forest expansion for biodiversity together with environmental considerations has stimulated a growing interest in ecologically sound forest planning and management practices (FAO 2012). The conservation of biodiversity in plantation forests is a key component of sustainable forest management, which is one of the foremost tools for achieving compatibility between forest industries and the provision of ecosystem services, including the conservation of forest biodiversity (MCPFE 2011; Lindenmayer et al. 2000). Sustainable forest management practices can be used to improve the value of plantation forests for biodiversity (Paritsis and Aizen 2008; Hartmann et al. 2010), but must be underpinned by a thorough understanding of the drivers of forest biodiversity. The full potential of plantations to contribute towards conservation objectives can only be realised when the ecology of native woodlands and their flora and fauna is understood, and the factors influencing forest biodiversity are identified. This, in turn, requires an understanding of the factors influencing the biodiversity of remaining native woodlands.

There is much interest in the extent to which plantation forests can support or protect biodiversity (Bremer and Farley 2010; Brockerhoff et al. 2008; Coote et al. 2012). While natural 
forests represent some of the richest and most biologically diverse ecosystems in the world, including more than half of all terrestrial species (MEA 2005; FAO 2012), and play a central role in the functioning of the biosphere (Larsson 2001), the highly managed nature of plantation forests means they may support less native biodiversity than naturally occurring forests (Hunter 1999; Lindenmayer and Hobbs 2004; Stephens and Wagner 2007; Paritsis and Aizen 2008). However, in countries where the extent of naturally occurring forest is limited, plantation forests may provide habitat for forest associated species and enhance overall landscape biodiversity, particularly when they are established in areas where the biodiversity value of the preceding land use is low (Stephens and Wagner 2007; Brockerhoff et al. 2008; Pawson et al. 2008; Sweeney et al. 2010). Several studies have suggested that plantation forests have the potential to benefit native biodiversity even where the planted tree species are exotic (Bremer and Farley 2010; O'Hanlon and Harrrington 2012; Humphrey 2005).

Although Ireland was once extensively forested, today forest cover accounts for less than $11 \%$ of its surface area. Eighty-seven percent of the forest cover in Ireland is comprised of plantations, the majority of which (97\%) are dominated by conifers (MCPFE et al. 2007), with nonnative Sitka spruce (Picea sitchensis) being the most frequently planted tree species. The remainder of Ireland's forest cover comprises semi-natural woodlands (Forest Service 2007). This makes plantation forests potentially of greater importance to forest biodiversity than in regions where forest cover is dominated by semi-natural woodland (Bremer and Farley 2010; Berndt et al. 2008). However, although Ireland's native woodlands are limited in their spatial extent, the value of their biodiversity is disproportionately high, providing a reference point against which more recently established forests can be compared.

Assessments of biodiversity are commonly used to gauge the impact of different forest management practices on biodiversity. Whether carried out for scientific, conservation or management purposes, the scope of biodiversity assessments is inevitably constrained by the resources available. In such cases, information about unsurveyed taxa may be inferred from known relationships with environmental variables or other taxonomic groups (surrogate taxa) (Wolters et al. 2006; Gardner 2010).

Biotic indicators include surrogate taxa (Lewandowski et al. 2010; van Weerd and de Haes 2010; Wolters et al. 2006), whose diversity can be used to infer the diversity of other taxa. This approach is most beneficial when the biodiversity of one or more relatively cryptic, inaccessible or hard-to-identify groups can be effectively estimated using data from a more easily surveyed group 
(Gioria et al. 2010; Rodrigues and Brooks 2007). Biodiversity studies investigating multiple taxa within the same study sites enable an assessment of the extent to which information derived from one taxon may inform us about another. Such detailed studies across a wide taxonomic range allow assessment of the adequacy of surveys that focus on one or a few species groups.

Previous studies that have investigated the usefulness of surrogacy have differing conclusions, some considering surrogate taxa to be a useful tool for providing data about unsurveyed taxa (Gioria et al. 2010; Rodrigues and Brooks 2007), and others cautioning that relationships between taxa are often too weak or too variable to infer information efficiently about one taxon from another (Carmel and Stoller-Cavari 2006; Andelman and Fagan 2000; Wolters et al. 2006). Cross-taxon or higher taxon surrogates may be more effective than surrogates based on environmental data (Rodrigues and Brooks 2007; Brennan et al. 2006), and studies that have considered surrogacy at relatively broad geographical scale have typically found more strongly in favour of surrogacy (Lewandowski et al. 2010; van Weerd and de Haes 2010).

The response of biodiversity to commercial plantation forests varies across taxonomic groups, and much of the evidence for this variation comes from meta-analysis of independent studies which consider individual taxa separately (Paillet et al. 2010; Paritsis and Aizen 2008). Very few studies report on the importance of plantation forests for more than one taxon simultaneously. We conducted a survey of the diversity in multiple taxonomic and functional groups (plants, invertebrates and birds) across the island of Ireland where commercial plantations are the dominant forest type. We also investigated associations between species richness of the different taxonomic groups in order to assess the predictive ability of each group as a biodiversity surrogate for remaining groups. The aims of this study were to assess the potential of plantation forests to provide habitat for biodiversity in an area where little native woodland remains, to identify ways of improving plantation forest management for biodiversity, and to test the validity of using cross-taxon surrogacy in the biodiversity assessment of plantation forests and native woodland.

\section{Methods}

\section{Study sites}

Twenty closed-canopy spruce- (Picea-) dominated plantation forest and 20 semi-natural woodlands were selected for study. All study sites were larger than 4 ha. These included ten Sitka 
spruce- (Picea sitchensis-) dominated plantation forests in their second rotation (hereafter referred to as Sitka spruce plantations), ten Norway spruce- (Picea abies-) dominated plantation forests (hereafter referred to as Norway spruce plantations), ten oak- (Quercus petraea-) dominated semi-natural woodlands (hereafter referred to as oak woodlands) and ten ash(Fraxinus excelsior-) dominated semi-natural woodlands (hereafter referred to as ash woodlands). Sites were widely distributed across the island of Ireland (Fig. 1).

Ten semi-natural woodlands were dominated by oak with birch and/or holly in the understory and occurred on reasonably well-drained acid soils. The other ten semi-natural woodland study sites were dominated by ash with oak and/or hazel in the understory and occurred on more base-rich soils. Oak and ash woodlands in the Republic of Ireland were selected on the basis of their presence on $1^{\text {st }}$ edition (c.1840s) Ordnance Survey maps, while those in Northern Ireland were selected from a database of ancient and long-established woodland (The Woodland Trust 2007). However, due to a lack of suitable sites, we included two woodlands that were not present on the $1^{\text {st }}$ edition maps or in the database. Following analysis we found that these woodlands did not differ significantly from the others and so results are presented for all woodlands. During the study, the native woodlands were all subject to little or no management.

\section{Data collection}

Surveys of ground vegetation (bryophytes and vascular plants), invertebrates (canopy spiders and beetles and active ground-dwelling spiders and Carabid beetles) and birds were conducted at the study sites during the summers of 2007 and 2008.

At each study site three $10 \mathrm{~m} \times 10 \mathrm{~m}$ plots were selected for survey of ground vegetation. Plots were located at least $50 \mathrm{~m}$ from the edge and at least $50 \mathrm{~m}$ apart. Within each plot, the percentage cover of each terrestrial plant species was estimated to the nearest $5 \%$. Below $5 \%$ two different cover-abundance units were distinguished: $3 \%$ (indicating cover of $1-5 \%$ ) and $0.5 \%$ (indicating cover $<1 \%$ ). For bryophytes only those species forming patches more than $10 \mathrm{~cm}^{2}$ were recorded. Species not forming patches of this size but which occurred frequently were also recorded. Nomenclature follows Stace (2010) for vascular plants and Paton (1999) for liverworts.

Pitfall traps were used to collect ground-dwelling spiders and Carabid beetles at all study sites. Although this method is widely used and is an efficient method, it should be noted that pitfall catches are a function of the activity, density and behaviour of each species rather than a measure of absolute abundance. 
Up to three sampling plots were located at each study site within $10 \mathrm{~m}$ of the ground vegetation survey plots. Each sampling plot comprised five pitfall traps spaced (pooled for analyses) approximately $2 \mathrm{~m}$ apart and consisted of a plastic cup, $7 \mathrm{~cm}$ in diameter and $9 \mathrm{~cm}$ in depth. A bulb corer of similar dimensions to the cup was used to make a hole in the ground in which to sink the cup so that it was flush with the soil surface and soil disturbance around the trap was minimized. Two drainage holes were cut horizontally, $1 \mathrm{~cm}$ from the top of the cup, and traps were filled with ethylene glycol to a depth of $1 \mathrm{~cm}$ to act as a killing and preserving agent. There was considerable animal disturbance ( $>80 \%$ trap loss) at two of the Sitka spruce study sites sampled during 2007 and so these sites were re-sampled during the same period in 2008. To reduce the impact of animal disturbance during the 2008 sampling period a combination of protective wire mesh boxes (mesh size was approximately $3 \mathrm{~cm}$ to allow ground-dwelling invertebrates to pass through) and wire mesh lids held $5 \mathrm{~cm}$ above the ground by plastic pegs and attached to electric fence units were used. To identify any potential influence of the protective devices or of sampling across years two further sites were re-sampled in 2008 that were located in close proximity to the disturbed sites, were of similar age class and had a full set of pitfall traps collected during the previous year and none was found. Analyses did not reveal any impact of these devices. All traps were set in mid-May of 2007 or 2008 and left in situ for nine weeks during which time the contents of all traps were collected approximately every three weeks. Catches were pooled across the nine weeks for analyses. Spiders and Carabid beetles were sorted from the pitfall samples and adults were identified to species level using Roberts (1993) and Luff (2007).

Spiders and beetles were sampled from forest canopies at 24 of the study sites (6 of each site type) using a canopy fogging technique that targeted one tree, located at least $50 \mathrm{~m}$ from the edge, at each study site. Canopy fogging is frequently used by researchers working on canopy invertebrates, as it provides access to invertebrate populations in forest canopies while minimising access-related disturbance. It is, however, limited by weather conditions and may overlook attached or sessile animals and does not sample groups that live within the tree itself (Stork and Hammond 1997). Using a petrol-driven fogging machine (SwingFog SN50-PE, SwingTec Ltd, Germany) a natural pyrethroid (Pybuthrin 33, Spray-Chem Ltd, Dublin) was dispersed in ultra-low volume droplets into the tree canopy for between 6 and 9 minutes. This insecticide is nonpersistent in the environment, has no phytotoxic effects and (at the levels used), and is not harmful to mammals or birds (Straw et al. 1996). Fallen invertebrates were then collected using an arrangement of 16 plastic sheets with a combined area of $24 \mathrm{~m}^{2}$ suspended $1 \mathrm{~m}$ from the ground 
under the fogged canopy. Plastic sheets were arranged around the target tree on the eight cardinal and ordinal compass bearings. These sheets were left in place for 3 hours after fogging and the catches from all sheets at each site were pooled. Samples were collected in situ using soft paintbrushes to brush invertebrates into bottles containing $70 \%$ alcohol before the insects could recover from the effects of the insecticide.

Birds were surveyed at all study sites during the breeding season using point counts (Bibby et al. 2000). Six (or, where forests were too small at one Norway spruce site and one ash woodland, 4 and 5 respectively) points were randomly placed a minimum of $100 \mathrm{~m}$ apart in edge and interior forest habitat. Point counts of birds were conducted on days without strong wind (less than Beaufort scale 4) or persistent rain and lasted for 10 minutes, during which time all birds seen and heard within $50 \mathrm{~m}$ of the observer were recorded and their distances from the observer noted. Each site was surveyed twice with one of the visits carried out between 0800 and 1100 hours, and the other between 1400 and 1700 hours and species richness was calculated as the cumulative number of species recorded over the two visits.

\section{Data analysis}

Abundance measures for the community analysis comprised species cover of plants and relative abundance (individual species abundance divided by total site abundance) of invertebrate groups. Distance (DISTANCE 6.0 Release 2) software was used to derive bird densities from field observations. Both the identity of a species and the habitat in which it is observed may affect the detectability of birds and so each species was assigned to one of four detection groups, depending on the habitat type, method of detection, the distribution of detections in five $10 \mathrm{~m}$ distance bands and knowledge of the species' ecology. Akaike's Information Criteria (AIC) was used to select between four models for fitting of the detection function: Uniform + Cosine, Uniform + Polynomial, Half normal + Hermite and Hazard-rate + Cosine (Buckland et al. 2001). For each site, the bird population densities of all species for both the early and late counts were calculated, and the density of a species taken as the maximum of these two values. Species richness was adjusted to the lowest sampling effort for ground invertebrates and birds ( 2 sample plots and 4 point counts respectively) using species accumulation curves and to the lowest total number of individuals caught $(n=15)$ for canopy invertebrates using individual based rarefaction curves to 
account for possible differences in vertical canopy structure. Analyses were carried out in R using the vegan package (Oksanen et al. 2010)

Species richness of all species and of forest-associated species (FAS) was calculated for each of the groups sampled in each forest type. For forest-associated species richness we identified ground vegetation species typical of woodland/forests, forest-associated grounddwelling spider and Carabid beetle species, canopy-dwelling spider and beetle conifer, broadleaved and deadwood specialist species and bird species with strong associations with all forest habitats in Ireland, or specialising in one type of forest habitat (e.g. coniferous or broadleaved) to the exclusion of the other.

Species richness was compared among forest types using generalised linear models (GLMs) in the statistical software $R$ ( $R$ Development Core Team 2012). The appropriate error term (normal, Poisson, negative binomial) for each analysis was selected by comparing Akaike's Information Criterion (AIC) and examining the ratio of deviance/residual degrees of freedom. Tukey pairwise comparisons were used to examine differences among forest types. Spatial autocorrelation of GLM residuals was examined by Moran's I in the ape package v.3.0-6 (Paradis et al. 2004) in R. In all instances Moran's I was not significant ( $P>0.05)$.

Species richness and forest-associated species richness values for each group were correlated with values for every other group separately. Since some of the datasets did not conform to parametric assumptions, non-parametric Spearman's rank correlations were used throughout. Significance values were not adjusted with e.g. the Bonferroni method after conducting multiple comparisons on the same data sets, because there are some mathematical and practical objections in the application of such corrections (Moran 2003). Correlations were not only evaluated with regard to their significance, but also their strength. Where $r>0.7$, such strong correlations in species richness between taxonomic groups may be considered as evidence that variation in the diversity of one group is mirrored strongly enough by the other to be useful for predictive purposes in biodiversity surveys (Sauberer et al. 2004; Heino 2010).

For each taxonomic group, assemblage composition across forest types was examined using Non-Metric Multidimensional Scaling (NMS) performed on a matrix of Bray-Curtis dissimilarities of abundance data (square root transformed and Wisconsin double standardization) using the vegan package (Oksanen et al. 2010) in R. Centroids for forest types were plotted to visualise assemblage differences. Stress values were examined to assess the accuracy in representation: $<0.05$ excellent; $<0.1$ good; $<0.2$ potentially useful; $>0.3$ close to arbitrary 
(Clarke and Warwick 1994). Differences between forest types in each ordination where tested by analysis of variance with the function adonis in vegan package which partitions sums of squares of a multivariate data set, directly analogous to MANOVA (multivariate analysis of variance) type analyses.

To explore the similarities in community composition among different taxonomic groups and to identify surrogate taxa, the Procrustes rotation method was used (Peres-Neto and Jackson 2001; Jackson 1995). The NMS scores of each taxonomic group were separately best fitted with the scores of all other taxonomic groups using rotation, reflection and dilation to find an optimal superimposition. Such a Procrustes rotation process minimises the residual sum-of-squares $\left(m_{12}\right)$ between the two matrix configurations (Peres-Neto and Jackson 2001). The value of the sum-ofsquared residuals between corresponding coordinates in both configurations can be used as a metric of correlation (Gower 1971); the lower the value, the greater the degree of association between the ordinations, i.e. the concordance between datasets. Using the protest function in vegan the best fit of two ordinations can be tested against a relationship occurring by chance (Jackson 1995). Protest uses a correlation-like statistic which can be interpreted similarly to the Pearson correlation index $r^{2}$ (Peres-Neto and Jackson 2001): larger-values of $r$ indicate a better concordance between two matrices and both matrices are identical if $r=1$.

\section{Results}

\section{Species richness}

A total of 574 species of plants and animals were recorded in the forest study sites, 206 of which were forest-associated species (FAS). These species included 158 species of vascular plant (50 FAS), 93 bryophytes (26 FAS), 107 ground-dwelling spiders (28 FAS), 42 canopy-dwelling spiders (14 FAS), 54 ground-dwelling beetles (12 FAS), 92 canopy-dwelling beetles (60 FAS) and 28 bird species (16 FAS).

Canopy-dwelling beetles showed significantly higher species richness in oak and ash seminatural woodlands than in spruce plantations. Bryophytes and birds also showed higher species richness in semi-natural woodlands than in plantations but, though SR was significantly higher in ash than both plantation forest types, SR in oak was only significantly higher than SS (Fig. 2, Table 1). Vascular plants only had higher SR than both plantation types in ash woodlands and this was only significant for SS. The remaining invertebrate groups showed similar species richness in semi- 
natural woodlands and plantations, with the exception of ground-dwelling spiders, which showed significantly higher species richness in semi-natural woodlands than in Sitka spruce plantations (Fig. 2, Table 1).

Similar patterns of species richness of forest-associated species were seen as for total species richness. Again, invertebrates were more closely matched in semi-natural woodlands and plantation forests than other groups, with the exception of beetles which showed significantly higher species richness in semi-natural woodlands (Fig. 3, Table 1).

\section{Community composition}

Species composition differed significantly between forest habitats for all groups (Fig. 4). The ordination of sites according to vascular plant species composition shows that the plant communities of spruce plantations were more variable than those of native woodlands. Sitka spruce sites were particularly distinct, with the communities for both ash and oak woodlands overlapping with those of Norway spruce plantations. Bryophyte communities in ash woodlands were separated from those in other woodland types, with the communities of both oak and Sitka spruce sites overlapping with those in Norway spruce. Ground beetles communities in the different forest sites were poorly distinguished from one another, but ground spiders in native woodland sites were broadly distinct from those in plantations, with communities in oak and Sitka spruce being more similar to one another than those in ash and Norway spruce. Canopy beetles and spiders in ash were distinct from those in spruce plantations, with canopy beetles in ash being distinct from those in oak. Birds in native woodlands were clearly distinct from communities in spruce sites.

\section{Cross-taxon surrogacy}

Following rotation of NMDS ordinations of any two taxonomic groups, Procrustes randomisation tests in PROTEST indicated significant concordances between assemblage ordinations of just fewer than half of the groups under investigation (Table 4). Although a number of the Procrustes concordances were highly significant, none were sufficiently strong $(r>0.7)$ to regard any taxonomic groups as surrogate taxa (Heino 2010; Sauberer et al. 2004) and birds did not show significant concordance with any other group tested. 


\section{Discussion}

\section{Species diversity}

The potential for plantation forests to support biodiversity is influenced by a number of factors including preceding land use, planted tree species and management practices (Bremer and Farley 2010; Brockerhoff et al. 2008). This study documents the ground vegetation, ground- and canopydwelling spider and beetle, and bird diversity of Sitka spruce plantations and Norway spruce plantations during the closed canopy stage of the forest cycle, and of unmanaged oak and ash semi-natural woodlands. Sitka spruce is the most commonly planted exotic conifer tree species in Ireland, and Norway spruce is the most commonly planted conifer in northern Europe (MCPFE 2011). Although no truly undisturbed natural woodland remains in Ireland, the oak and ash woodlands included in this study were unmanaged forest sites that had, for the most part, been established for at least 150 years. By comparison the plantation forests were highly managed commercial production forests.

Each of the taxon groups included in this study responded to forest type in slightly different ways. Both spruce-dominated forest plantation types supported ground-dwelling beetle and canopy-dwelling spider species richness similar to native woodlands, but the same was not true for other groups investigated which differed significantly between forest types. Within the invertebrate taxa investigated no consistent trend in species richness was observed between forest types. Ground-dwelling beetles and canopy-dwelling spiders showed no significant differences between native woodlands and spruce plantations in this study which may reflect the absence of forest specialist species in Ireland. Canopy-dwelling beetles were the only invertebrate group for which species richness was consistently higher in oak and ash woodlands than in forest plantations. This group was composed of generalists whose occurrence was more influenced by geographic location than by local stand factors (Oxbrough et al. 2010). Spiders, which are generalist predators and are more dependent on habitat structure and prey availability than the actual tree species they inhabit (Halaj et al. 1998, 2000), had similar species richness in Sitka spruce plantations than in native woodlands. Variation in species composition of spider communities is related to prey abundance and size (Halaj et al. 1998; Uetz 1979). Beetles, on the other hand, are more diverse in their foraging strategies and previous studies have shown that the negative impacts of forest plantations particularly impact beetles (Wiezik et al. 2007). As well as 
predators, they include many species that feed on specific types of plants, fungi, wood or detritus. The distribution of such species can be constrained by plant species composition and chemistry of substrate as much as by structural elements of forest habitat (Moore et al. 1991). Phytophagous beetles in particular are generally adapted to inhabiting a specific host tree species, due to the chemical composition of the edible vegetation and the defensive compounds produced by plants (Strong 1984).

The species richness of vascular plants was higher in ash woodlands than in Sitka spruce plantation forests, but lower than in Norway spruce plantations. Understory and physical attributes of plantation forests do differ from those of natural woodlands (Aubin et al. 2008) and greater habitat complexity in natural woodlands has been shown to provide more suitable habitat than managed forests for some groups (Wiezik et al. 2007; Stephens and Wagner 2007; Veinotte et al. 2003).

Species richness of forest-associated bryophytes, vascular plants, canopy-dwelling beetles and birds was also higher in oak and ash woodlands than in Sitka spruce dominated plantations, though species richness values in Norway spruce plantations were sometimes more similar to those of native woodlands. These patterns are most likely related to the lower light levels in spruce-dominated plantations. The understory of conifer plantations is typically less structurally complex than in natural woodlands (Aubin et al. 2008) where higher light levels can contribute to increased plant diversity and understory structure (Riegel et al. 1995). This, in turn, is important for the biodiversity of invertebrates and birds (Hardtle et al. 2003; Messier et al. 1998; Sweeney et al. 2010).

Previous studies that used meta-analysis to investigate species richness across a number of taxonomic groups have found that species dependent on forests, such as bryophytes and saproxylic beetles are negatively affected by forest management but others such as vascular plants and birds are not (Paillet et al. 2010; Stephens and Wagner 2007; Paritsis and Aizen 2008). It is very likely that the absence of a consistent effect of forest plantations on forest biodiversity in the present study is related to the rarity of forest specialist species in Ireland, which has relatively few forest specialists compared with other parts of Europe, and forests are inhabited mainly by generalist species adapted to living in a range of habitat types (Mitchell 2006; Fuller et al. 2007; Kelly 2008).

Community composition differed significantly between forest plantations and native woodlands for all groups with the exception of ground-dwelling beetles. Compared to the trends 
in species richness, the trends in community composition between native oak and ash woodlands and plantations were more similar among the taxonomic groups with the majority having different communities in native woodlands and plantations. For the canopy-dwelling spiders, native woodlands had different communities to pure spruce plantations while canopy-dwelling beetles were significantly different between native woodlands and spruce plantations. For the canopydwelling spiders, differences in habitat structure and prey availability between coniferous and broadleaved trees are likely to be the reason for the patterns observed. The differences for canopy-dwelling beetles may be related to the abundance of prey for predators in spruce, combined with the lack of beetle guilds which specifically feed on conifer tissues, resulting in different suites of species. Ground-dwelling beetles were the only group that did not show any clear separation between native woodlands and plantations. The lack of forest specialist beetles may be the reason for this lack of distinction. For birds there was clear separation between native woodlands and spruce plantations, which was probably related to the lower structural diversity of plantations, as well as differences in the diet preferences of certain species (Sweeney et al. 2010).

\section{Cross-taxon surrogacy}

Ground-dwelling beetles stood out during the investigation of species richness cross-taxon surrogacy, having the fewest correlations with any other group for either total species richness or forest-associated species richness. Previous work has shown this group not to be greatly influenced by forest type which is reflected in the findings of the present study (Oxbrough et al. 2010). While almost half of the combinations of the other groups were significantly correlated, indicating a broad similarity in their responses in terms of species richness at the coarse scale of all forest types combined, none of the groups had correlation coefficients greater than 0.7 . This is the level above which one taxonomic group may be considered a potential surrogate for another (Sauberer et al. 2004). This is most likely due to the different levels of specialisation and mobility among the different taxonomic groups under investigation. When the data for forest-associated species only was interrogated, broadly similar patterns were found, however in this case forestassociated species richness of birds and canopy-dwelling beetles were highly significantly correlated and had a correlation coefficient $r=0.740$, suggesting that the use of forest-associated birds as a surrogate for forest-associated canopy-dwelling beetles may be appropriate in biodiversity monitoring. 
While the Procrustes analyses across all sites showed that community composition of most of the taxa varies in a broadly similar way between sites, comparisons of the variation in species richness and forest-associated species richness between the different taxonomic groups revealed few significant correlations, and none with a correlation coefficient greater than 0.7 . A correlation between two taxa might be due to the species richness and assemblage of the taxa responding to some of the same, broad differences in habitat between the forest types.

Previous work has shown that cross-taxon surrogacy is most appropriate across large geographic scales, where the range of environmental variation is likely to be greater (Lewandowski et al. 2010). At small scales, animal and plant distributions are influenced by unmeasurable (stochastic) as well as measurable factors. Predicting the status or distribution of one taxon using another as a surrogate introduces the potential for twice as much stochastically-derived error in resulting estimates as would relying on a suite of environmental variables that have a direct effect on the taxon under investigation.

\section{Conclusions}

Our data show that, although some relatively easily surveyed groups, such as vascular plants and birds, are congruent with a number of the other taxa that the similarities in response are not strong enough to warrant use of these taxa as surrogates. Taxon surrogacy is only useful where it predicts diversity and assemblage of hard-to-survey taxa with groupings of sites of a similar habitat. However, congruence within site-types, as measured by inter-taxon species richness correlations, was low in the current study. This suggests that the taxa we studied cannot be used as surrogates of one another at the scales we studied. In order to capture a wide range of biotic variation, assessments of biodiversity in Irish forests must encompass several taxonomic groups, and/or rely on the use of non-biotic (structural or functional) indicators of diversity.

The species richness of spruce-dominated plantations can be as high as is found in seminatural woodlands, though the general trend was for oak and ash woodlands to support different communities to plantations. Since forest plantations are the predominant forest cover throughout much of the world, this indicates that the species composition of forests is being altered by the use of exotic conifer species. Where similar or greater numbers of species were supported in plantations, the communities differed from those in native woodlands. Ground-dwelling beetles did not follow this pattern, having similar numbers of species in spruce plantations and native 
woodlands, more forest-associated species in spruce than in oak woodlands, and a lack of distinct communities in plantations and native woodlands. Investigation of cross-taxon surrogacy revealed that ground-dwelling beetles also had the fewest significant correlations with the other groups, most of which were significantly correlated, indicating a broad similarity in the responses of these other groups. The overall patterns observed across the range of taxa included in this study, which possess a variety of lifestyles, mobility and habitat requirements suggests that while plantation forests are can host species richness similar to semi-natural woodlands targeted management is required to ensure that they provide habitat for native woodland flora and fauna.

\section{Acknowledgements}

This research was funded by the Dept. of Food, Agriculture \& the Marine and the Irish Research Council for Science, Engineering \& Technology under the National Development Plan 2007 - 2013. We thank Coillte and the many private forest owners in Ireland who granted permission for use of their forest sites in this study. We also thank Lauren Fuller for her contribution to manuscript preparation. 


\section{References}

Andelman SJ, Fagan WF (2000) Umbrellas and flagships: Efficient conservation surrogates or expensive mistakes? Proc Natl Acad Sci U S A 97 (11):5954-5959

Aubin I, Messier C, Bouchard A (2008) Can plantations develop understory biological and physical attributes of naturally regenerated forests? Biol Cons 141 (10):2461-2476

Berndt L, Brockerhoff E, Jactel H (2008) Relevance of exotic pine plantations as a surrogate habitat for ground beetles (Carabidae) where native forest is rare. Biodiversity and Conservation 17 (5):11711185

Bibby CJ, Burgess ND, Hill DA (2000) Bird Census Techniques. Academic Press, London,

Bremer L, Farley K (2010) Does plantation forestry restore biodiversity or create green deserts? A synthesis of the effects of land-use transitions on plant species richness. Biodiversity and Conservation 19 (14):3893-3915

Brennan KEC, Ashby L, Majer JD, Moir ML, Koch JM (2006) Simplifying assessment of forest management practices for inverebrates: How effective are higher taxon and habitat surrogates for spiders following prescribed burning? For Ecol Man 213:138-154

Brockerhoff E, Jactel H, Parrotta J, Quine C, Sayer J (2008) Plantation forests and biodiversity: oxymoron or opportunity? Biodiversity and Conservation 17 (5):925-951

Brukas V, Felton A, Lindbladh M, Sallnäs O (2013) Linking forest management, policy and biodiversity indicators - A comparison of Lithuania and Southern Sweden. For Ecol Man 291 (0):181-189

Buckland ST, Anderson DR, Burnham KP, Laake JL, Borchers DL, Thomas L (2001) Introduction to Distance Sampling: estimating abundance of biological populations. Oxford University Press, Oxford

Carmel Y, Stoller-Cavari L (2006) Comparing environmental and biological surrogates for biodiversity at a local scale. Israel J Ecol Evol 52:11-27

Clarke KR, Warwick RM (1994) Change in marine communities: an approach to statistical analysis and interpretation. Plymouth Marine Laboratory, Plymouth.

Coote L, French LJ, Moore KM, Mitchell FJG, Kelly DL (2012) Can plantation forests support plant species and communities of semi-natural woodland? Forest Ecology and Management 283:86-95

European Commission (2011) Forestry in the EU and the world - A statistical portrait. pp107 (Ed Union., P. O. o. t. E.).

Fabbio G, Merlo M, Tosi V (2003) Silvicultural management in maintaining biodiversity and resistance of forests in Europe-the Mediterranean region. J Environ Manage 67 (1):67-76

FAO (2012) State of the World's Forests 2012. Food and Agriculture Organization of the United Nations. Forest Service (2007) National Forest Inventory, Republic of Ireland. 
Fuller RJ, Gaston KJ, Quine CP (2007) Living on the edge: British and Irish woodland birds in a European context. Ibis 149:53-63

Gardner T (2010) Monitoring forest biodiversity: Improving conservation through ecologically responsible management. Earthscan,

Gioria M, Schaffers A, Bacaro G, Feehan J (2010) The conservation value of farmland ponds: predicting water beetle assemblages using vascular plants as a surrogate group. Biol Cons 143:1125-1133

Gower JC (1971) Statistical methods of comparing different multivariate analyses of the same data. In: Hodson FR, Kendall DG, Tautu P (eds) Mathematics in the Archaeological and Historical Sciences. Edinburgh University Press, UK, pp 138-149

Halaj J, Ross DW, Moldenke AR (1998) Habitat structure and prey availability as predictors of the abundance and community organization of spiders in western Oregon forest canopies. J Arachnol $26: 203-220$

Halaj J, Ross DW, Moldenke AR (2000) Importance of habitat structure to the arthropod food-web in Douglas-fir canopies. Oikos 90:139-152

Hardtle W, von Oheimb G, Westphal C (2003) The effects of light and soil conditions on the species richness of the ground vegetation of deciduous forests in northern Germany (Schleswig-Holstein). For Ecol Man 182:327-338

Hartmann H, Daoust G, Bigué B, Messier C (2010) Negative or positive effects of plantation and intensive forestry on biodiversity: a matter of scale and perspective. The Forestry Chronicle 86:354-364

Heino J (2010) Are indicator groups and cross-taxon congruence useful for predicting biodiversity in aquatic ecosystems? Ecological Indicators 10:112-117

Humphrey JW (2005) Benefits to biodiversity from developing old-growth conditions in British upland spruce plantations: a review and recommendations. Forestry 78:33-53

Hunter MJ (1999) Maintaining Biodiversity in Forest Ecosystems. Cambridge University Press,

Jackson DA (1995) PROTEST: a PROcrustean randomization TEST of community environment concordance. Ecoscience 2:297-303

Kelly TC (2008) The origin of the avifauna of Ireland. The Irish Naturalists' Journal Special Supplement 2008:97-107

Klenner W, Arsenault A, Brockerhoff EG, Vyse A (2009) Biodiversity in forest ecosystems and landscapes: A conference to discuss future directions in biodiversity management for sustainable forestry. For Ecol Man 258, Supplement (0):S1-S4

Kuuluvainen T (2009) Forest Management and Biodiversity Conservation Based on Natural Ecosystem Dynamics in Northern Europe: The Complexity Challenge. AMBIO 38 (6):309-315

Larsson TB (2001) Biodiversity evaluation tools for European forests. 
Lewandowski AS, Noss RF, Parsons DR (2010) The Effectiveness of Surrogate Taxa for the Representation of Biodiversity. Conserv Biol 24 (5):1367-1377

Lindenmayer DB, Hobbs RJ (2004) Fauna conservation in Australian plantation forests - a review. Biol Cons 119:151-168

Lindenmayer DB, Margules CR, Botkin DB (2000) Indicators of Biodiversity for Ecologically Sustainable Forest Management. Conserv Biol 14 (4):941-950

Luff M (2007) RES Handbook Volume 4 Part 2: The Carabidae (Ground Beetles) of Britain and Ireland. Field Studies Council, Shropshire, UK,

MCPFE (2011) State of Forests 2011: Europe's Status \& Trends inSustainable Forest Management in Europe.

MCPFE, UNECE, FAO (2007) State of Europe's Forests 2007: The MCPFE Report on Sustainable Forest Management in Europe. Warsaw

MEA (2005) Millennium Ecosystem Assessment (2005) Ecosystems and human well-being: Biodiversity synthesis. Washington (D. C.): World Resources Institute.

Messier C, Parent S, Bergeron Y (1998) Effects of overstory and understory vegetation on the understory light environment in mixed boreal forests. J Veg Sci 9:511-520

Mitchell FJG (2006) Where did Ireland's trees come from? Biology and Environment 106:251-259

Moore R, Warrington S, Whittaker JB (1991) Herbivory by insects on oak trees in pure stands compared with paired mixtures. Journal of Applied Ecology. J Appl Ecol 28:290 - 304

Moran MD (2003) Arguments for rejecting the sequential Bonferroni in ecological studies. Oikos 100:403405

O'Hanlon R, Harrrington TJ (2012) Macrofungal diversity and ecology in four Irish forest types. Fungal Ecology 5:499-508

Oksanen J, Blanchet FG, Kindt R, Legendre P, O'Hara RB, Simpson GL, Solymos P, Henry M, Stevens H, Wagner H (2010) Vegan: Community Ecology Package. R package Version 1.17-2. http://CRAN.Rproject.org/package = vegan.

Oxbrough A, Irwin S, Kelly TC, O'Halloran J (2010) Ground dwelling invertebrates in reforested conifer plantations. For Ecol Man 259:2111-2121

Paillet $Y$, Bergès L, Hjältén J, Ódor P, Avon C, Bernhardt-Römermann M, Bijlsma R-J, De Bruyn LUC, Fuhr M, Grandin ULF, Kanka R, Lundin L, Luque S, Magura T, Matesanz S, Mészáros I, Sebastià MT, Schmidt W, Standovár T, Tóthmérész B, Uotila A, Valladares F, Vellak KAI, Virtanen R (2010) Biodiversity Differences between Managed and Unmanaged Forests: Meta-Analysis of Species Richness in Europe. Conserv Biol 24 (1):101-112

Paradis E, Claude J, Strimmer K (2004) APE: Analyses of Phylogenetics and Evolution in R language. Bioinformatics 20:289-290 
Paritsis J, Aizen MA (2008) Effects of exotic conifer plantations on the biodiversity of understory plants, epigeal beetles and birds in Nothofagus dombeyi forests. For Ecol Man 255 (5-6):1575-1583 Paton JA (1999) The liverwort flora of the British Isles. Harley Books, Colchester,

Pawson S, Brockerhoff E, Meenken E, Didham R (2008) Non-native plantation forests as alternative habitat for native forest beetles in a heavily modified landscape. Biodiversity and Conservation 17 (5):11271148

Peres-Neto PR, Jackson DA (2001) How well do multivariate data sets match? The advantages of a Procrustean superimposition approach over the Mantel test. Oecologia 129:169-178

Riegel GM, Miller RF, Krueger WC (1995) The Effects of Aboveground and Belowground Competition on Understory Species Composition in a Pinus ponderosa Forest. For Sci 41 (4):864-889

Roberts M (1993) The Spiders of Great Britain and Ireland (compact edition). Part One. Harley Books, Colchester

Rodrigues ASL, Brooks TM (2007) Shortcuts for biodiversity conservation planning: the effectiveness of surrogates. Annu Rev Ecol Syst 38:713-737

Sauberer N, Zulka KP, Abensperg-Traun M, Berg H-M, Bieringer G, Milasowszky N, Moser D, Plutzar C, Pollheimer M, Storch C, Tröstl R, Zechmeister H, Grabherr G (2004) Surrogate taxa for biodiversity in agricultural landscapes of eastern Austria. Biol Cons 117 (2):181-190

Stace C (2010) New Flora of the British Isles, 3rd Edition. Cambridge University Press. Cambridge

Stephens SS, Wagner MR (2007) Forest Plantations and Biodiversity: A Fresh Perspective. J For 105 (6):307313

Stork N, Hammond P (1997) Sampling arthropods from tree crowns by fogging with knockdown insecticides: lessons from studies of oak tree beetle assemblages in Richmond Park (UK). In: Stork N, Adis J, Didham R (eds) Canopy Arthropods. Chapman and Hall, London, pp 3 - 26

Straw NA, Fielding NJ, Waters A (1996) Phytotoxicity of insecticides used to control aphids on Sitka spruce, Picea sitchensis (Bong.) Carr. Crop Protection 15:451-459

Strong DR (1984) Insects on plants. Community patterns and mechanisms. Blackwell Scientific Publications, Oxford,

Sweeney OFM, Wilson MW, Irwin S, Kelly TC, O'Halloran J (2010) Are bird density, species richness and community structure similar between native woodlands and non-native plantations in an area with a generalist bird fauna? Biodiversity and Conservation 19:2329-2342

The Woodland Trust (2007) Back on the Map: An Inventory of Ancient and Long Established Woodland for Northern Ireland - Preliminary Report. The Woodland Trust, Bangor

Uetz G (1979) The influence of variation in litter habitats on spider communities. Oecologia 40 (1):29-42 
van Weerd M, de Haes HAU (2010) Cross-taxon congruence in tree, bird and bat species distributions at a moderate spatial scale across four tropical forest types in the Philippines. Biodiversity and Conservation 19:3393-3411

Veinotte C, Freedman B, Maass W, Kirstein F (2003) Comparison of the ground vegetation in spruce plantations and natural forest in the Greater Fundy Ecosystem, New Brunswick. Can Field Nat 117:531-540

Wiezik M, Svitok M, Dovčiak M (2007) Conifer introductions decrease richness and alter composition of litter-dwelling beetles (Coleoptera) in Carpathian oak forests. For Ecol Man 247 (1-3):61-71 Wolters V, Bengtsson J, Zaitsev AS (2006) Relationship among the species richness of different taxa. Ecol 87 (8):1886-1895 


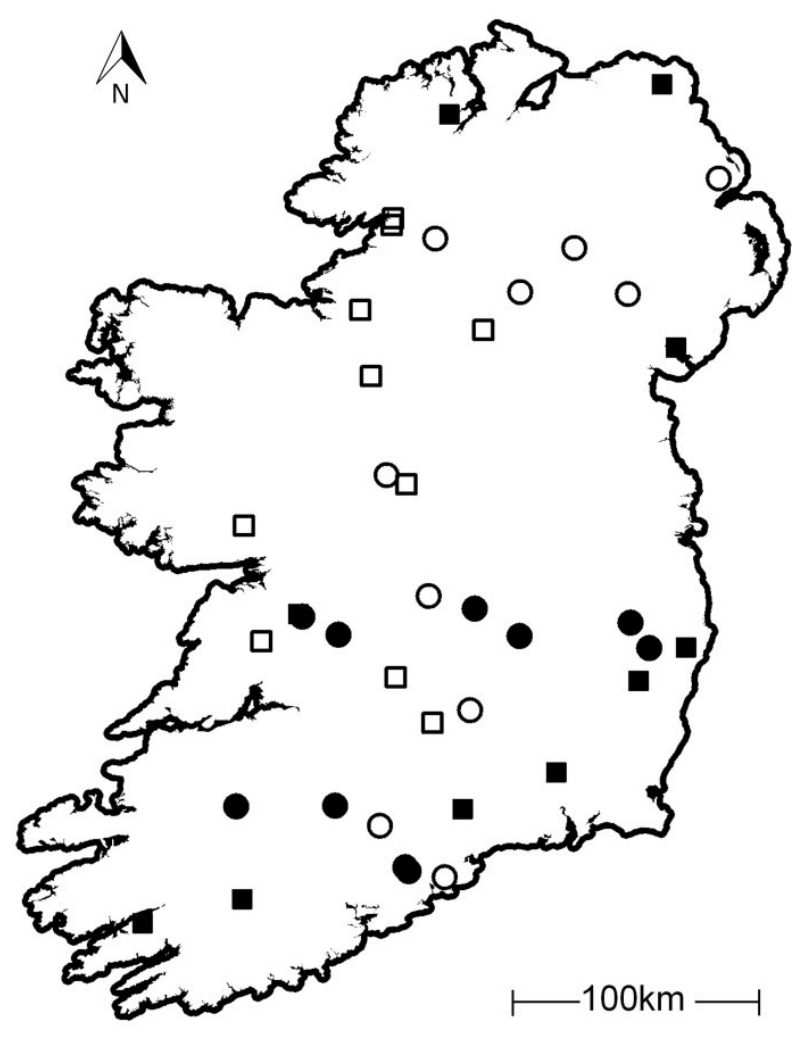

Fig. 1 Map of Ireland showing plantation and semi-natural forest study sites. $\bullet=$ Sitka sprucedominated plantations, $\mathrm{O}=$ Norway spruce-dominated plantations, $\mathbf{\square}=$ Oak-dominated seminatural woodlands and $\square=$ Ash-dominated semi-natural woodlands. 

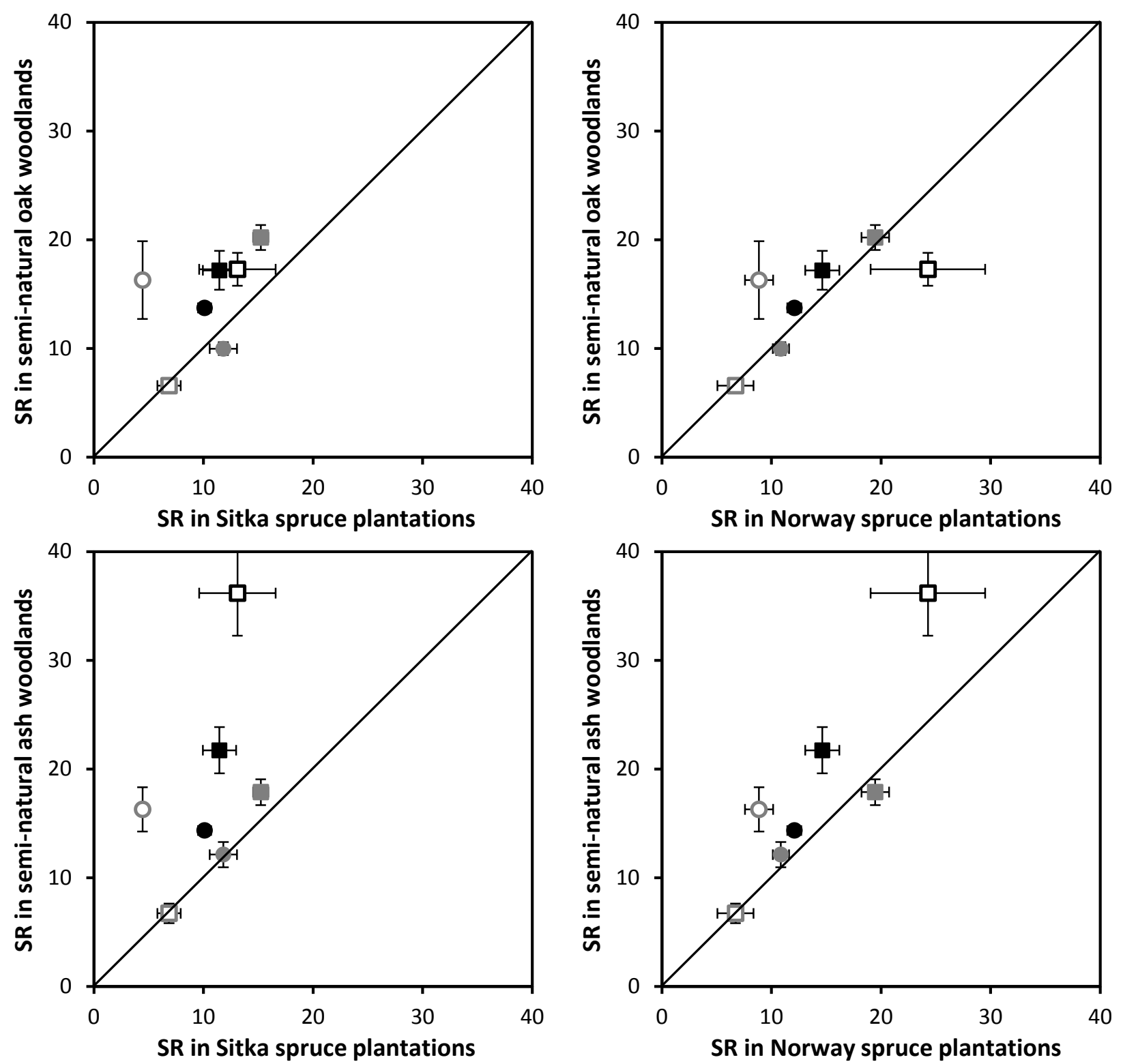

Fig. 2 Mean species richness ( \pm s.e.) of the seven groups in spruce-dominated plantations in relation to mean species richness of these groups in semi-natural woodlands. $\mathbf{m}=$ Bryophytes, $=$ Vascular plants, $=$ = Ground-dwelling spiders, =Canopy-dwelling spiders, $\bullet=$ Ground-dwelling beetles, = Canopy-dwelling beetles, $\bullet=$ Birds. In these graphs the diagonal line indicates equal species richness in both forest types and the position of a group above or below this line suggests a positive influence on species richness of one of the forest types in comparison with the other. 

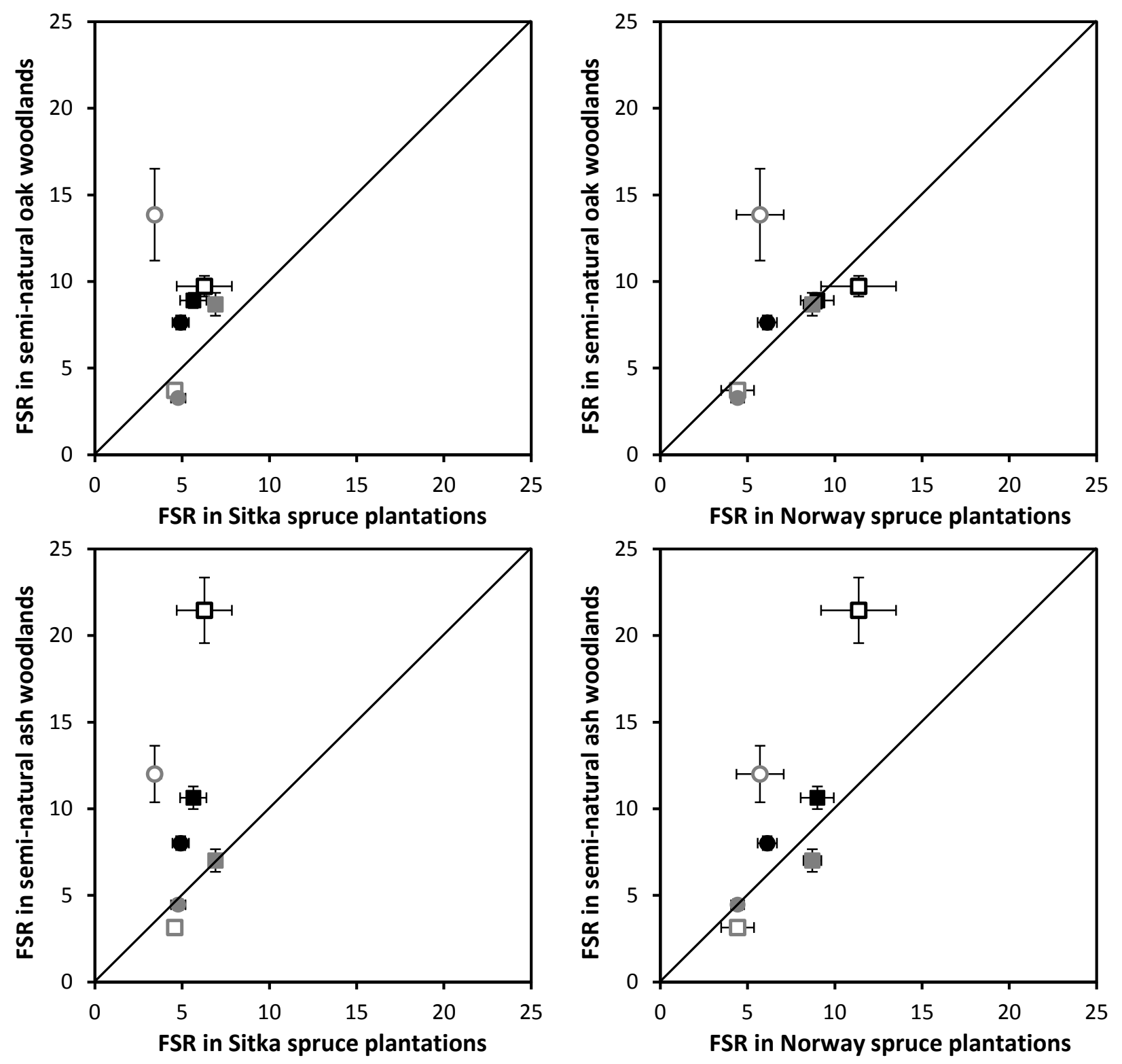

Fig. 3 Mean total species richness ( \pm s.e.) of forest-associated species (FSR) for each of the 7 groups in spruce-dominated plantations in relation to mean species richness of these groups in seminatural woodlands. = = Bryophytes, =Vascular plants, = =Ground-dwelling spiders, = Canopydwelling spiders, $\bullet=$ Ground-dwelling beetles, =Canopy-dwelling beetles, $\bullet=$ Birds. In these graphs the diagonal line indicates equal species richness in both forest types and the position of a group above or below this line suggests a positive influence on species richness of one of the forest types in comparison with the other. 


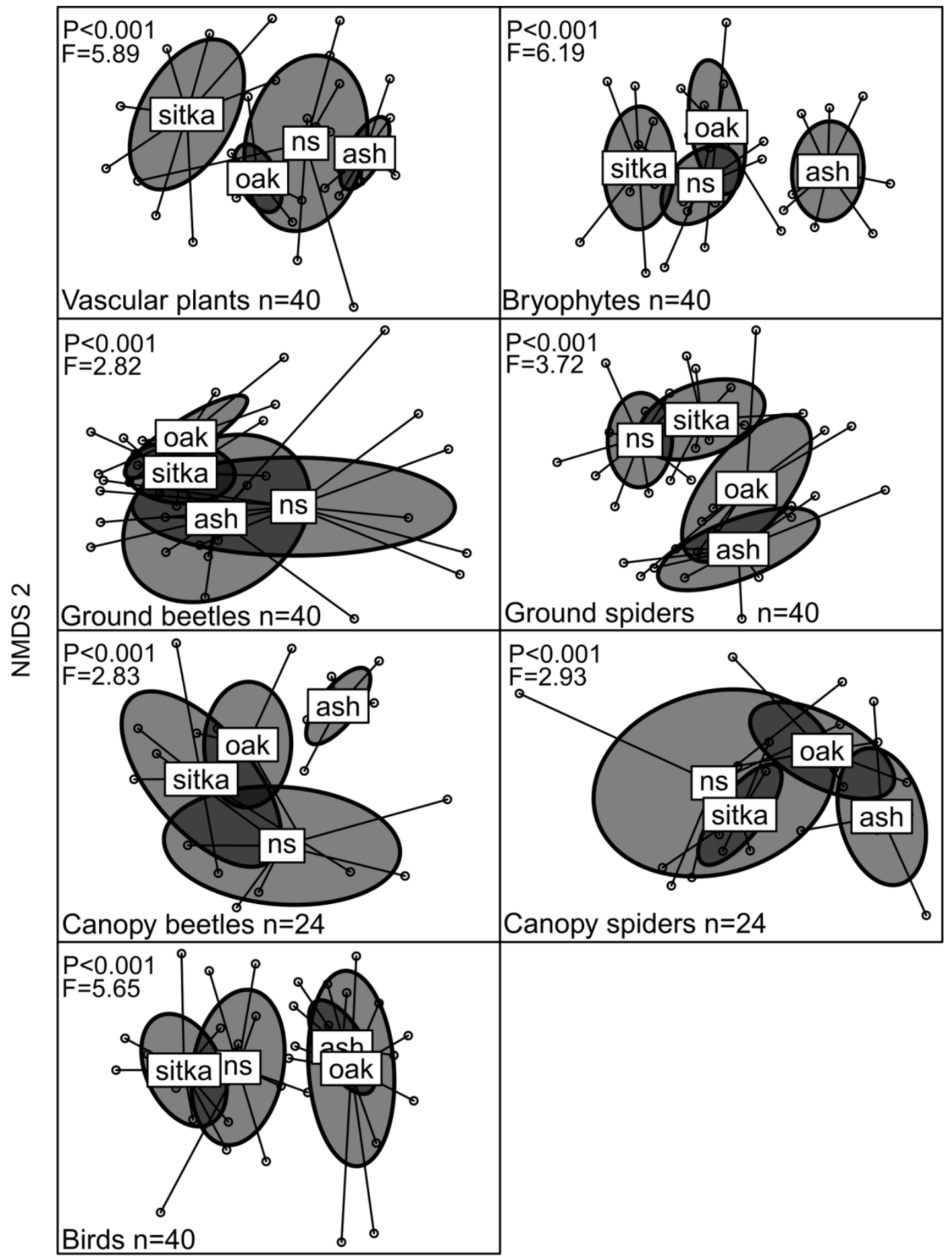

NMDS 1

Fig. 4 Non-Metric Multidimensional Scaling (NMDS) ordinations of assemblage composition of vascular plants (stress $=0.19$ ), bryophytes (stress $=0.18$ ), ground beetles (stress $=0.14$ ), ground spiders (stress $=0.23$ ), canopy beetles (stress $=0.21$ ), canopy spiders (stress $=0.13$ ) and birds (stress $=0.22$ ) in sites of four forest types (ash = ash-dominated semi-natural woodlands, oak =oakdominated semi-natural woodlands, ns = Norway spruce dominated plantations, sitka = Sitka spruce dominated plantations). Points are sampled sites with lines connecting to habitat centroids. 
Values for $F$ (test statistic) and $P$ refer to results of ANOVAs on group differences. Shaded ellipses represent standard deviation-based confidence intervals from the centroid of each habitat. 
Table 1 Results of Generalised Linear Models (Test statistic ( $\chi^{2}$ or $F$ ) and $p$-value) comparing species richness of 'all species' and 'forest-associated species' among forest types (SS = Sitka spruce-dominated plantations, NS = Norway spruce-dominated plantations, Oak = oak-dominated semi-natural woodlands, Ash = ash-dominated semi-natural woodlands). Tukey pairwise comparisons were used to define homogenous sub-sets (a-c ranked highest to lowest); forest types? that share a lowercase letter do not differ significantly $(P>0.05)$.

\begin{tabular}{|c|c|c|c|c|c|c|c|c|}
\hline Taxa & Variable & SS & NS & Oak & Ash & Test & Statistic & P-value \\
\hline \multirow[t]{2}{*}{ Bryophytes } & All species ${ }^{1}$ & $\mathrm{a}$ & $a b$ & $\mathrm{bc}$ & c & $\mathrm{F}$ & 7.20 & $<0.001$ \\
\hline & Forest species ${ }^{1}$ & $\mathrm{a}$ & $b$ & $b$ & $b$ & $\mathrm{~F}$ & 11.35 & $<0.001$ \\
\hline \multirow[t]{2}{*}{ Vascular plants } & All species ${ }^{1}$ & $\mathrm{a}$ & $a b$ & a & $b$ & $\mathrm{~F}$ & 7.88 & $<0.001$ \\
\hline & Forest species ${ }^{1}$ & $\mathrm{a}$ & $b$ & $a b$ & c & $\mathrm{F}$ & 18.00 & $<0.001$ \\
\hline \multirow[t]{2}{*}{ Ground spiders } & All species ${ }^{1}$ & $\mathrm{a}$ & $b$ & $b$ & $a b$ & $\mathrm{~F}$ & 5.10 & 0.005 \\
\hline & Forest species ${ }^{1}$ & $\mathrm{a}$ & a & $a$ & a & $\mathrm{F}$ & 3.46 & 0.026 \\
\hline \multirow[t]{2}{*}{ Canopy spiders } & All species ${ }^{3}$ & $\mathrm{a}$ & a & a & a & $\chi^{2}$ & 0.05 & 0.997 \\
\hline & Forest species $^{1}$ & $\mathrm{a}$ & a & a & a & $\mathrm{F}$ & 0.79 & 0.512 \\
\hline \multirow[t]{2}{*}{ Ground beetles } & All species ${ }^{2}$ & $\mathrm{a}$ & a & $a$ & a & $\mathrm{F}$ & 1.21 & 0.320 \\
\hline & Forest species ${ }^{2}$ & $\mathrm{a}$ & $a b$ & $b$ & a & $\mathrm{F}$ & 4.64 & 0.008 \\
\hline \multirow[t]{2}{*}{ Canopy beetles } & All species ${ }^{4}$ & $\mathrm{a}$ & $b$ & c & c & $\chi^{2}$ & 51.66 & $<0.001$ \\
\hline & Forest species ${ }^{1}$ & $\mathrm{a}$ & a & $b$ & $b$ & $\mathrm{~F}$ & 15.26 & $<0.001$ \\
\hline \multirow[t]{2}{*}{ Birds } & All species² & $a$ & $\mathrm{~b}$ & $b c$ & c & $\mathrm{F}$ & 14.21 & $<0.001$ \\
\hline & Forest species ${ }^{2}$ & $\mathrm{a}$ & $a b$ & $b c$ & c & $\mathrm{F}$ & 11.56 & $<0.001$ \\
\hline
\end{tabular}

Variable superscript indicates which model type used; 1 = square root , $2=$ linear, $3=$ poisson, 4 = negative binomial. 
Table 2 Correlations between species richness of each group. Significant correlations are highlighted in bold text.

\begin{tabular}{clcrrrrr}
\hline & & $\begin{array}{c}\text { Vascular } \\
\text { plants }\end{array}$ & $\begin{array}{r}\text { Ground } \\
\text { spiders }\end{array}$ & $\begin{array}{c}\text { Canopy } \\
\text { spiders }\end{array}$ & $\begin{array}{r}\text { Ground } \\
\text { beetles }\end{array}$ & $\begin{array}{c}\text { Canopy } \\
\text { beetles }\end{array}$ & Birds \\
\hline \multirow{2}{*}{ Bryophytes } & $r$ & $\mathbf{0 . 5 4 6}$ & 0.286 & -0.178 & 0.231 & $\mathbf{0 . 6 4 1}$ & $\mathbf{0 . 5 0 6}$ \\
& $\mathrm{P}$ & $\mathbf{0 . 0 0 0}$ & 0.074 & 0.406 & 0.152 & $\mathbf{0 . 0 0 1}$ & $\mathbf{0 . 0 0 1}$ \\
Vascular plants & $r$ & & 0.228 & -0.065 & 0.276 & $\mathbf{0 . 5 1 6}$ & $\mathbf{0 . 3 7 2}$ \\
& $\mathrm{P}$ & & 0.157 & 0.764 & 0.085 & $\mathbf{0 . 0 1 0}$ & $\mathbf{0 . 0 1 8}$ \\
Ground spiders & $r$ & & & & 0.178 & 0.338 & $\mathbf{0 . 4 5 4}$ \\
& $\mathrm{P}$ & & & & -0.217 & 0.106 & $\mathbf{0 . 0 0 3}$ \\
Canopy spiders & $r$ & & & & -0.148 & -0.028 & -0.193 \\
& $\mathrm{P}$ & & & & 0.489 & 0.895 & 0.367 \\
Ground beetles & $r$ & & & & & -0.056 & -0.088 \\
& $\mathrm{P}$ & & & & & 0.794 & 0.590 \\
Canopy beetles & $r$ & & & & & & $\mathbf{0 . 6 2 9}$ \\
& $\mathrm{P}$ & & & & & & $\mathbf{0 . 0 0 1}$ \\
\hline
\end{tabular}


Table 3 Correlations between species richness of forest-associated species for each group. Significant correlations are highlighted in bold text.

\begin{tabular}{|c|c|c|c|c|c|c|c|}
\hline & & $\begin{array}{l}\text { Vascular } \\
\text { plants }\end{array}$ & $\begin{array}{l}\text { Ground } \\
\text { spiders }\end{array}$ & $\begin{array}{l}\text { Canopy } \\
\text { spiders }\end{array}$ & $\begin{array}{l}\text { Ground } \\
\text { beetles }\end{array}$ & $\begin{array}{l}\text { Canopy } \\
\text { beetles }\end{array}$ & Birds \\
\hline \multirow{2}{*}{ Bryophytes } & $r$ & 0.653 & 0.214 & -0.267 & 0.173 & 0.561 & 0.515 \\
\hline & $\mathrm{P}$ & 0.000 & 0.186 & 0.208 & 0.286 & 0.004 & 0.001 \\
\hline \multirow{2}{*}{ Vascular plants } & $r$ & & 0.088 & -0.287 & 0.047 & 0.633 & 0.583 \\
\hline & $\mathrm{P}$ & & 0.589 & 0.175 & 0.775 & 0.001 & 0.000 \\
\hline \multirow{2}{*}{ Ground spiders } & $r$ & & & 0.302 & -0.342 & 0.169 & 0.218 \\
\hline & $\mathrm{P}$ & & & 0.152 & 0.031 & 0.431 & 0.177 \\
\hline \multirow{2}{*}{ Canopy spiders } & $r$ & & & & -0.346 & -0.401 & -0.401 \\
\hline & $\mathrm{P}$ & & & & 0.098 & 0.052 & 0.052 \\
\hline \multirow{2}{*}{ Ground beetles } & $r$ & & & & & -0.173 & -0.209 \\
\hline & $\mathrm{P}$ & & & & & 0.419 & 0.197 \\
\hline \multirow{2}{*}{ Canopy beetles } & $r$ & & & & & & 0.740 \\
\hline & $P$ & & & & & & 0.000 \\
\hline
\end{tabular}


Table 4 Correlation coefficient of a symmetric Procrustes rotation ( $r$ ) and level of significance $(P)$ evaluating the concordance between the NMDS scores (calculated for each investigated taxonomic group sampled on a site level in all forest types combined) after Procrustes rotation. Correlations with canopy spiders and canopy beetles comprise 24 sites, all other correlations comprise 40 sites. Significant results $(P \leq 0.05)$ are indicated in black text. Significant correlations are highlighted in bold text.

\begin{tabular}{|c|c|c|c|c|c|c|c|}
\hline & & $\begin{array}{c}\text { Vascular } \\
\text { plants }\end{array}$ & $\begin{array}{l}\text { Ground } \\
\text { spiders }\end{array}$ & $\begin{array}{l}\text { Canopy } \\
\text { spiders }\end{array}$ & $\begin{array}{l}\text { Ground } \\
\text { beetles }\end{array}$ & $\begin{array}{l}\text { Canopy } \\
\text { beetles }\end{array}$ & Birds \\
\hline \multirow{2}{*}{ Bryophytes } & $r$ & 0.533 & 0.447 & 0.429 & 0.221 & 0.475 & 0.140 \\
\hline & $\mathrm{P}$ & 0.001 & 0.001 & 0.026 & 0.246 & 0.007 & 0.703 \\
\hline \multirow{2}{*}{ Vascular plants } & $r$ & & 0.444 & 0.446 & 0.265 & 0.519 & 0.144 \\
\hline & $\mathrm{P}$ & & 0.001 & 0.006 & 0.119 & 0.004 & 0.717 \\
\hline \multirow{2}{*}{ Ground spiders } & $r$ & & & 0.365 & 0.230 & 0.435 & 0.188 \\
\hline & $P$ & & & 0.086 & 0.226 & 0.023 & 0.470 \\
\hline \multirow{2}{*}{ Canopy spiders } & $r$ & & & & 0.474 & 0.440 & 0.398 \\
\hline & $P$ & & & & 0.022 & 0.013 & 0.060 \\
\hline \multirow{2}{*}{ Ground beetles } & $r$ & & & & & 0.271 & 0.178 \\
\hline & $P$ & & & & & 0.300 & 0.473 \\
\hline \multirow{2}{*}{ Canopy beetles } & $r$ & & & & & & 0.375 \\
\hline & $P$ & & & & & & 0.067 \\
\hline
\end{tabular}

